Article

\title{
Blood Pressure Lowering Effect of Cuban Policosanol is Accompanied by Improvement of Hepatic Inflammation, Lipoprotein Profile, and HDL Quality in Spontaneously Hypertensive Rats
}

\author{
Kyung-Hyun Cho 1,2,3,*,+ (iD), Dhananjay Yadav 1,2,3,+, Suk-Jeong Kim 1,2,3 and Jae-Ryong Kim 4 \\ 1 Department of Medical Biotechnology, Yeungnam University, Gyeongsan 712-749, Korea; \\ dhanyadav16481@gmail.com (D.Y); superiorgene@ynu.ac.kr (S.-J.K) \\ 2 Research Institute of Protein Sensor, Yeungnam University, Gyeongsan 712-749, Korea \\ 3 LipoLab, Daehak-Ro 280, Gyeongsan 712-749, Korea \\ 4 Department of Biochemistry and Molecular Biology, Smart-Aging Convergence Research Center, \\ College of Medicine, Yeungnam University, Daegu 705-717, Korea; kimjr000@gmail.com \\ * Correspondence: chok@yu.ac.kr; Tel: +82-53-810-3026; Fax: +82-53-814-3026 \\ + Co-first authors.
}

Academic Editor: Francesca Giampieri

Received: 1 April 2018; Accepted: 1 May 2018; Published: 3 May 2018

\begin{abstract}
We investigated the antihypertensive effect of policosanol on spontaneously hypertensive rats (SHR). For this, we analyzed blood pressure, blood lipid, and lipoprotein properties in male SHR after consumption of Cuban policosanol (PCO). The experimental groups were as follows: normotensive Wistar Kyoto (WKY) control, SHR group fed normal diet (ND), SHR group fed $20 \mathrm{mg}$ of PCO, SHR group fed $100 \mathrm{mg}$ of PCO, and SHR group fed $200 \mathrm{mg}$ of PCO per kg of body weight. After eight weeks, the SHR control group showed gradual increases up to $22 \%$ in systolic blood pressure (SBP) and $17.6 \%$ in the diastolic blood pressure (DBP) compared with values at week 0 . However, policosanol consumption had a dose-dependent reduction effect on SBP and also reduced DBP up to $16 \%$ in a dose-dependent manner. Heart rate (HR) bpm increased by six percent in the SHR control, whereas the $20 \mathrm{mg}$, $100 \mathrm{mg}$, and $200 \mathrm{mg}$ of policosanol groups showed a reduction of $36 \%, 28 \%$, and $34 \%$ respectively. Although serum total cholesterol (TC) level of SHR was not affected by policosanol consumption $(70-80 \mathrm{mg} / \mathrm{dL}$ ), serum triglyceride (TG) level significantly decreased in the SHR + $200 \mathrm{mg}$ of PCO group. Serum high-density lipoprotein cholesterol (HDL-C) level was also significantly elevated by policosanol consumption. The \% HDL-C/TC ratio was elevated in the policosanol group up to $67-70 \%$, whereas the SHR control group showed a ratio of $58 \%$. Serum cholesteryl ester transfer protein (CETP) activity was reduced by policosanol in a dose-dependent manner. Although the serum glutamate oxaloacetate transaminase (GOT)/glutamate pyruvate transaminase (GPT) were similar across all groups, policosanol consumption caused reduction of reactive oxygen species (ROS) levels in hepatic tissue. The SHR control group showed a 2.1-fold higher serum C-reactive protein (CRP) level than the WKY group, whereas the CRP level decreased in the SHR $+200 \mathrm{mg}$ of PCO group (up to 45\%) than SHR control group. Aldosterone level was reduced in the policosanol group (up to 34\%) in a dose-dependent manner compared to the control. In conclusion, eight weeks of policosanol consumption in SHR resulted in remarkable reduction of blood pressure, serum aldosterone, and serum TG levels along with the elevation of HDL-C and improvement of hepatic inflammation.
\end{abstract}

Keywords: spontaneously hypertensive rats; policosanol; lipoproteins; hypertension; hepatic inflammation 


\section{Introduction}

High blood pressure is a global risk factor for coronary artery disease and metabolic syndrome and is associated with high oxidative stress and aortic stiffness. Dyslipidemia and hypertension are hallmarks of metabolic syndrome. New onset hypertension was preceded by dyslipidemia [1]. High triglyceride (TG) and low-density lipoprotein cholesterol (LDL-C) levels along with a low high-density lipoprotein-cholesterol (HDL-C) level are strongly associated with the development of hypertension [1,2].

Oxidative stress is strongly associated with hypertension as an underlying causative factor [3]. Although the role of oxidative stress in the development of hypertension has not been fully elucidated, endothelial dysfunction is deeply involved in hypertension. HDL is a potent antioxidant molecule in the blood, and it can ameliorate endothelial dysfunction to exert vasoprotective functions. It is well known that HDL mediates many pleiotropic functions to protect against cardiovascular disease and hypertension and possesses cholesterol efflux and NO production activities [4].

The development of a new agent that can simultaneously lower blood pressure and improve the lipid profile for treatment of cardiovascular disease (CVD) and hypertension is a major research goal. However, until now, there has been no promising pharmaceutical or nutraceutical to treat hypertension and hyperlipidemia simultaneously.

It has been previously reported that policosanol is effective in reducing the risk of CVD raising HDL-C and lowering LDL-C levels. A recent meta-analysis of randomized controlled trials from 22 studies including 1886 subjects concluded that policosanol could significantly reduce TC and LDL-C as well as increase HDL-C levels [5].

Encapsulation of policosanol by reconstituted HDL (policosanol-rHDL) was reported to enhance anti-oxidant and anti-glycation activities, resulting in inhibition of cellular senescence. Policosanol-rHDL (final concentration of nine micromolars of policosanol) showed more potent antioxidant activity than vitamin C (final $100 \mu \mathrm{M}$ ) in a previous study [6]. In a hypercholesterolemic zebrafish model, policosanol supplementation for nine weeks resulted in lowering of serum TC and TG levels and elevation of HDL-C via CETP inhibition, and amelioration of fatty liver changes and reactive oxygen species (ROS) production [7]. Although the exact mechanism of policosanol on the lowering of lipid levels and blood pressure has not been fully identified; however, a few of studies have evaluated that policosanol involves various pathways such as down-regulation of HMG-CoA reductase [8], CETP inhibition $[9,10]$ and renin-angiotensin-aldosterone system that might help in reducing lipid and blood pressure level [11]. However, the precise mechanism of this effect should be investigated more in detail molecular level.

In a previous study on human subjects, Cuban policosanol treatment unexpectedly reduced blood pressure in healthy male participants [9]. In order to confirm the blood pressure lowering effect of policosanol in a hypertension animal model, we supplemented policosanol to spontaneously hypertensive rats (SHR).

SHR are the most widely used animal model to study hypertension accompanied by vascular oxidative stress [12]. Oxidative stress precedes a rise in blood pressure and contributes to the development of hypertension. We hypothesized that antioxidant treatment such as policosanol in SHR reduces oxidative stress to prevent the development of high blood pressure and improve the lipid profile.

In order to confirm the blood pressure lowering effect of policosanol detail, the policosanol was supplemented to SHR (12-weeks-old) at three dosages (20, 100, and $200 \mathrm{mg} / \mathrm{kg}$ of body weight). The effects of policosanol on heart rate (HR), arterial blood pressure, serum lipid profile, and hepatic inflammation were also examined between the groups. 


\section{Results}

\subsection{Blood Pressure and Heart Rate}

At week 0, all SHR groups showed similar ranges of SBP and DBP (around 187-190 mmHg and 144-151 mmHg, respectively) while normotensive Wistar Kyoto (WKY) rats showed normal ranges of SBP and DBP (around $117 \mathrm{mmHg}$ and $89 \mathrm{mmHg}$, respectively). During the eight-week consumption period, the SHR control showed approximately 1.2-fold increases in SBP and DBP (around $228 \mathrm{mmHg}$ and $178 \mathrm{mmHg}$ respectively), as shown in Table 1 . However, the policosanol groups showed reduction of blood pressure in a dose-dependent manner. Specifically, the $200 \mathrm{mg}$ of policosanol group showed the lowest SBP and DBP at eight weeks up to sixteen percent reduction from its initial level $(p<0.001)$, whereas the $20 \mathrm{mg}$ and $100 \mathrm{mg}$ groups showed a four percent increase and five percent decrease, in SBP. DBP also increased by $17.6 \%$ in the SHR control group at eight weeks. However, $100 \mathrm{mg}$ and $200 \mathrm{mg}$ of policosanol consumption reduced DBP in a dose-dependent manner around 12-16\% reduction compared to week 0. (Table 1).

Table 1. Changes in SBP and DBP during eight weeks in the study groups

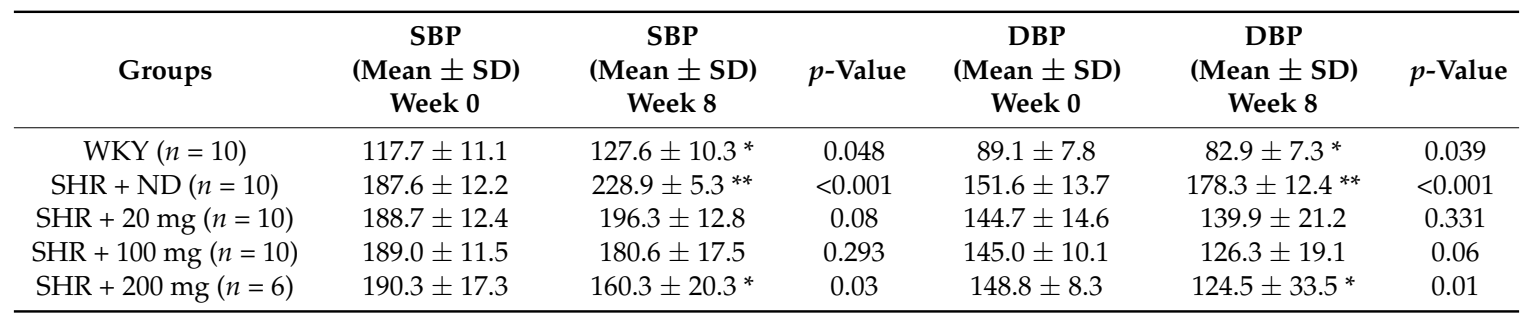

SBP, systolic blood pressure; DBP, diastolic blood pressure; WKY, normotensive Wistar Kyoto; SHR, Spontaneously hypertensive rats. $p$-Values calculated from the paired $t$-test at week 0 and week 8 of therapy. ${ }^{* *} p<0.001$, compared with week $0, * p<0.05$ compared with week 0 .

At week 0, all SHR groups had similar HRs (bpm) of around 305-341 bpm, whereas WKY rats had a HR of $242 \pm 22 \mathrm{bpm}$. At week 8, the SHR + ND group had an even six percent higher HR, whereas the policosanol group had a reduced HR compared with that at week 0 . The $20 \mathrm{mg}$ of policosanol group showed a 36\% reduction in HR at week 8, whereas the $100 \mathrm{mg}$ and $200 \mathrm{mg}$ of policosanol groups showed reduction of $28 \%$ and $34 \%$ respectively, at week 8 (Figure 1 ).

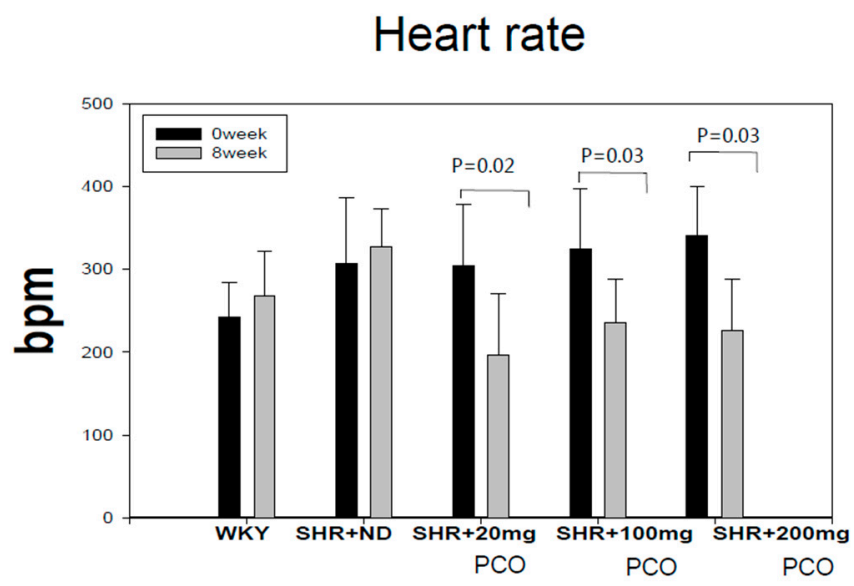

Figure 1. Changes in heart rate (HR) during eight weeks of policosanol supplementation. bpm, beats per minute; ND, normal diet; PCO, policosanol.

As shown in Figure 2, tail flow rates at week 0 were similar among all groups around (11-15 $\mu \mathrm{L} / \mathrm{min})$. At week 8, tail flow rate increased 1.6-fold in the SHR + ND group in a time-dependent 
manner, whereas the policosanol groups showed significant reduced flow rates up to $30-47 \%$ in a dose-dependent manner. The SHR $+200 \mathrm{mg}$ of policosanol group showed the slowest flow rate around $(7 \mu \mathrm{L} / \mathrm{min})$, whereas the SHR + ND group showed a flow rate of $20 \mu \mathrm{L} / \mathrm{min}$.

Flow rate in tail

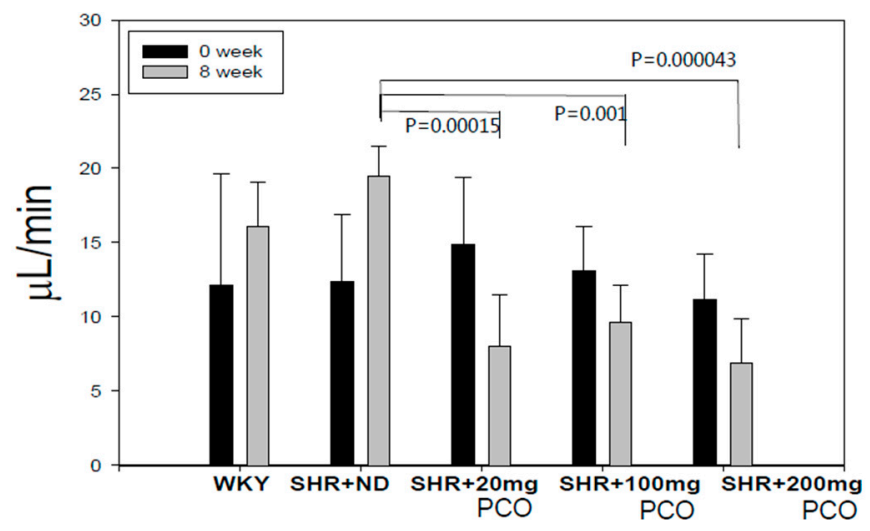

Figure 2. Changes in flow rate in tail during eight weeks of policosanol supplementation. ND, normal diet; PCO, policosanol.

At week 0 blood volumes in the tail were similar among all groups (around 40-50 $\mu \mathrm{L}$ ) (Figure 3). At week 8, WKY rats showed a 1.6-fold increase in tail blood volume compared with week 0 , whereas the SHR + ND group showed the highest increase around 2.3-fold at week 8 up to $110 \pm 21 \mu \mathrm{L}$. However, the policosanol groups showed reduction of tail blood volume. The $200 \mathrm{mg}$ of policosanol group showed the lowest tail blood volume around $41 \pm 10 \mu \mathrm{L}$ with the highest significance (Figure 3).

\section{Blood volume in tail}

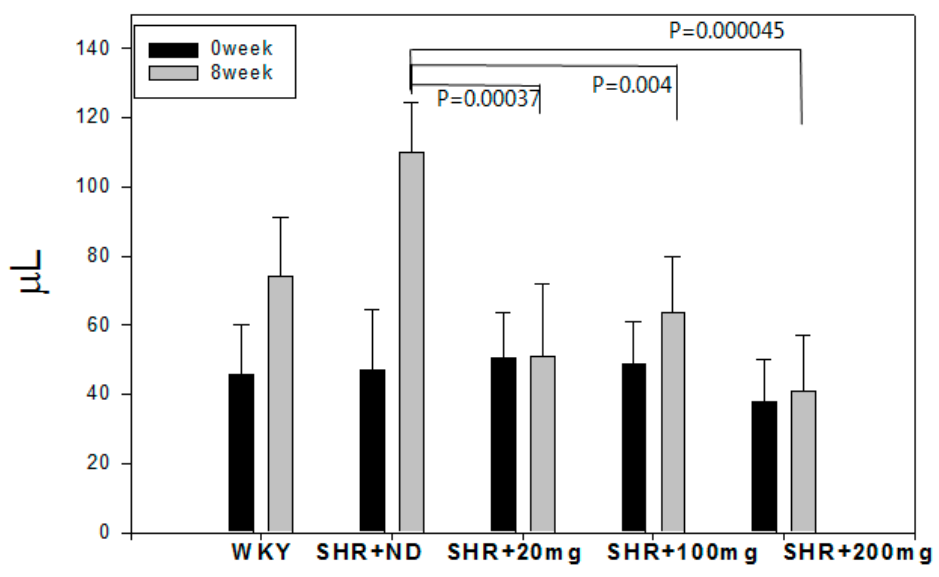

Figure 3. Changes in blood volume in tail eight weeks of policosanol supplementation. ND, normal diet; PCO, policosanol.

\subsection{Serum Lipid Profile}

There was no difference in water and food consumption in all groups during the eight weeks. WKY rats showed a 1.8-fold increase in plasma TC level (around $133 \mathrm{mg} / \mathrm{dL}$ ) than the SHR + ND group, and all SHR groups with or without policosanol consumption had similar TC level (around 73-76 mg/dL) at week 8. The SHR + ND group showed a 1.4-fold higher plasma TG level than the WKY group. Policosanol consumption reduced the TG level in a dose-dependent manner. 
The $200 \mathrm{mg}$ of policosanol group showed the lowest TG level-up to 19\% lower than that of the SHR + ND group. At week 8, as shown in Table 2, the SHR + ND group (44 mg/dL) showed a 35\% lower HDL-C level than WKY rats $(68 \mathrm{mg} / \mathrm{dL})$. However, HDL-C level was elevated after policosanol consumption in a dose-dependent manner up to $52 \mathrm{mg} / \mathrm{dL}$ in the $100 \mathrm{mg}$ and $200 \mathrm{mg}$ of policosanol groups. The HDL-C/TC ratio (\% HDL-C) also increased upon policosanol consumption up to $70 \%$ in the SHR + $200 \mathrm{mg}$ of policosanol group. The SHR control group showed a two-fold higher \% TG/HDL-C ratio than the WKY group. However, the TG/HDL-C ratio was significantly reduced (up to $22 \%$ ) to approximately $1.5 \pm 0.1$ upon policosanol consumption in a dose-dependent manner in the SHR + $200 \mathrm{mg}$ of policosanol group.

Table 2. Body weight changes and biochemical parameters in the study animals at week $8^{1}$.

\begin{tabular}{cccccc}
\hline \multirow{2}{*}{ Group } & $\mathbf{1}$ & $\mathbf{2}$ & $\mathbf{3}$ & $\mathbf{4}$ & $\mathbf{5}$ \\
\cline { 2 - 6 } & $\begin{array}{c}\text { WKY } \\
(\boldsymbol{n}=\mathbf{1 0})\end{array}$ & $\begin{array}{c}\text { SHR + ND } \\
(\boldsymbol{n}=\mathbf{1 0})\end{array}$ & $\begin{array}{c}\text { SHR + 20mg } \\
(\boldsymbol{n}=\mathbf{1 0})\end{array}$ & $\begin{array}{c}\text { SHR + 100mg } \\
(\boldsymbol{n}=\mathbf{1 0})\end{array}$ & $\begin{array}{c}\text { SHR + 200mg } \\
(\boldsymbol{n}=\mathbf{1 0})\end{array}$ \\
\hline Body weight & & & & & \\
week 0 & $313 \pm 10$ & $288 \pm 8$ & $294 \pm 7$ & $291 \pm 7$ & $293 \pm 13$ \\
week 8 & $409 \pm 10$ & $378 \pm 8$ & $384 \pm 7$ & $375 \pm 6$ & $374 \pm 7$ \\
TC (mg/dL) & $133 \pm 3$ IIIII & $75 \pm 3$ & $75 \pm 4$ & $73 \pm 3$ & $74 \pm 5$ \\
TG (mg/dL) & $61 \pm 4$ II & $83 \pm 7$ & $89 \pm 8$ & $77 \pm 9$ & $68 \pm 3^{*}$ \\
HDL-C (mg/dL) & $67 \pm 6$ IIII & $44 \pm 3$ & $44 \pm 4$ & $52 \pm 4 *$ & $52 \pm 4^{*}$ \\
\% HDL-C & $48 \pm 4$ & $58 \pm 3$ & $60 \pm 5$ & $69 \pm 3 *$ & $70 \pm 3^{*}$ \\
TG/HDL-C & $0.9 \pm 0.1$ IIIII & $1.9 \pm 0.1$ & $2.1 \pm 0.2$ & $1.6 \pm 0.1 * *$ & $1.5 \pm 0.1^{*}$ \\
LDL-C 2 & $58 \pm 4$ IIIII & $14 \pm 2.3$ & $12 \pm 4.6$ & $8 \pm 3.2^{*}$ & $7 \pm 1.8^{*}$ \\
Glucose (mg/dL) & $131 \pm 15$ & $161 \pm 22$ & $149 \pm 25$ & $153 \pm 23$ & $162 \pm 14$ \\
GOT (U/L) & $25 \pm 3$ & $28 \pm 3$ & $19 \pm 2$ & $30 \pm 4$ & $30 \pm 4$ \\
GPT (U/L) & $20 \pm 0.3$ & $20 \pm 0.5$ & $21 \pm 0.4$ & $20 \pm 0.4$ & $21 \pm 0.4$ \\
CRP (ng/L) & $476 \pm 25$ III & $988 \pm 48$ & $670 \pm 40 *$ & $660 \pm 32 *$ & $546 \pm 29^{* *}$ \\
\hline
\end{tabular}

1 Data are expressed as mean \pm SD. Significance was obtained from independent samples t-test. IIIII, $p<0.001$ vs. SHR + ND; III,$p<0.01$ vs. SHR + ND; II, $p<0.05$ vs. SHR + ND, ${ }^{* * *} p<0.001$ vs. SHR + ND; ${ }^{* *} p<0.01$ vs. SHR + ND; ${ }^{*} p<0.05$ vs. SHR + ND. ${ }^{2}$ LDL-C, calculated from Friedewald formula: LDL-C $=$ TC-(HDL-C + (TG/5)). CRP, C-reactive protein; HDL-C, high-density lipoprotein cholesterol; LDL-C, low-density lipoprotein cholesterol; TC, total cholesterol; TG, triglycerides; GOT, glutamate oxaloacetate transaminase; GPT, glutamate pyruvate transaminase.

Serum GOT level was similar between the WKY and SHR control groups. However, the $20 \mathrm{mg}$ of policosanol group showed a 33\% reduction in GOT level, although the effect was not dose-dependent manner. Moreover, the GPT level was not significantly different between the WKY and SHR groups.

The SHR control group showed a 2.1-fold higher CRP level than the WKY group. However, the serum CRP level was significantly reduced upon policosanol consumption in a dose-dependent manner (Table 2). The $200 \mathrm{mg}$ of policosanol group showed a $45 \%$ lower CRP level than the SHR control group.

\subsection{Serum CETP Activity}

At week 2, the SHR control group showed higher CETP activity than WKY rats, as shown in Figure 4. At eight weeks, the SHR + ND group showed slightly increased CETP activity up to $16 \pm 1 \%$ CE-transfer. However, CETP activity was reduced upon policosanol consumption in a dose-dependent manner at week 8 . The $200 \mathrm{mg}$ of policosanol group showed significant reduction of CETP activity up to $10 \pm 0.5 \%$ CE-transfer as shown in Figure 4 . The $20 \mathrm{mg}$ and $100 \mathrm{mg}$ of policosanol groups showed significant reductions of CETP activity at week 8 (12 $\pm 0.6 \%$ CE-transfer). 
CE-transfer assay (rat plasma)

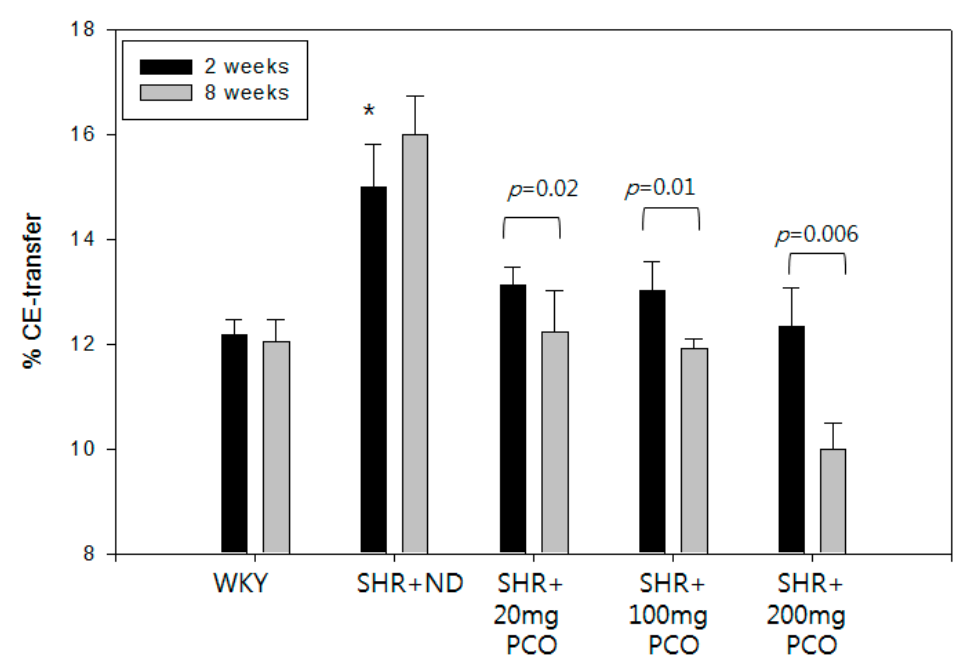

Figure 4. CE-transfer activity of WKY rats and SHR plasma after eight weeks of policosanol supplementation. Data shown are the mean $\pm \mathrm{SD}$ of three independent experiments performed in duplicate. CE-transfer from $\left[{ }^{3} \mathrm{H}\right]-\mathrm{HDL}(50 \mu \mathrm{g}$ of apoA-I, 30,000 CPM) to human LDL (50 $\mu \mathrm{g}$ of protein) by rat plasma.

\subsection{Antioxidative Activity of Lipoproteins}

After policosanol consumption, paraoxonase activity for HDL in the policosanol groups were elevated by $27.5 \%, 26.7 \%$, and $31 \%$, respectively, compared to the control group, as shown in Figure 5. This result implies that antioxidant activity was elevated in SHR group after consumption of policosanol.

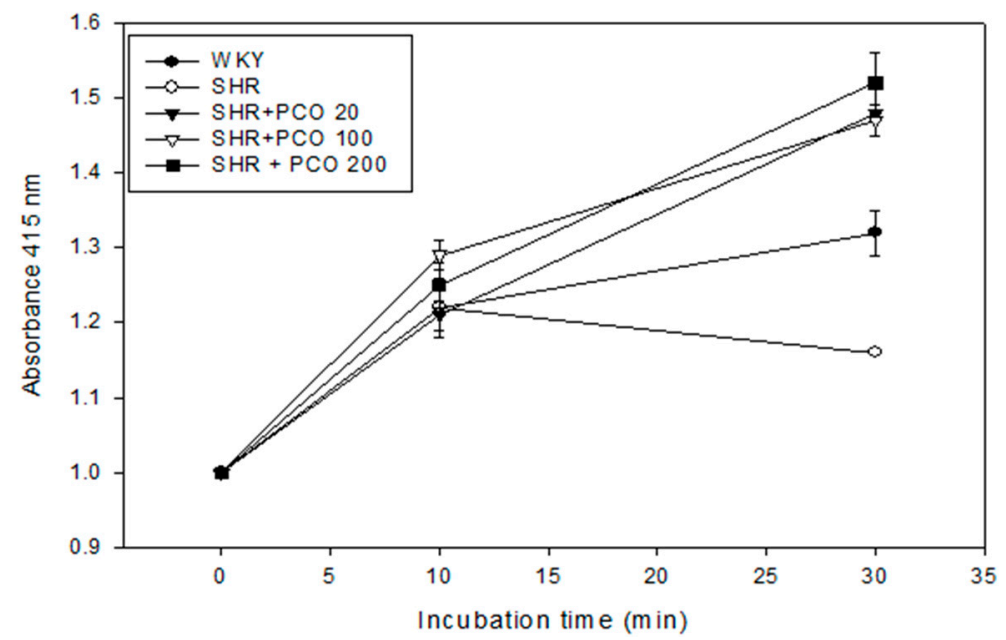

Figure 5. Changes of the paraoxonase activity in HDL after eight weeks of policosanol consumption in different groups.

\subsection{Protein, TC, and TG Compositions of Lipoproteins}

WKY rats showed higher total protein (TP) and total cholesterol (TC) contents in LDL, HDL and $\mathrm{HDL}_{3}$ fractions (Table 3). However, interestingly, the SHR control showed a higher TG content than the WKY group. In LDL fractions, the SHR + ND group showed the highest TP, TC, and TG levels. However, policosanol consumption caused gradual reductions of TC and TG levels in LDL in a 
dose-dependent manner. In $\mathrm{HDL}_{2}$, SHR showed only $45 \%$ lower TC and 21\% higher TG levels than WKY rats. Policosanol consumption caused significant elevation of TC and reduction of TG levels. In $\mathrm{HDL}_{3}$, the SHR group showed 24\% lower TC and 33\% higher TG levels than the WKY group. However, policosanol consumption (200 mg of policosanol group) caused gradual elevation of TC in $\mathrm{HDL}_{3}$ up to 1.4-fold more elevation than SHR control group. Lastly, TG content gradually decreased in the policosanol groups in a dose-dependent manner.

Table 3. Lipid and protein compositions in lipoprotein profile at week 8 .

\begin{tabular}{ccccccc}
\hline \multirow{2}{*}{ Group } & & $\mathbf{1}$ & $\mathbf{2}$ & $\mathbf{3}$ & $\mathbf{4}$ & $\mathbf{5}$ \\
\cline { 3 - 7 } & & $\begin{array}{c}\mathbf{W K Y} \\
(\boldsymbol{n}=\mathbf{1 0})\end{array}$ & $\begin{array}{c}\text { SHR + ND } \\
(\boldsymbol{n}=\mathbf{1 0})\end{array}$ & $\begin{array}{c}\text { SHR + 20 } \mathbf{~ g} \\
(\boldsymbol{n}=\mathbf{1 0})\end{array}$ & $\begin{array}{c}\text { SHR + 100 } \mathbf{~ m g} \\
(\boldsymbol{n}=\mathbf{1 0})\end{array}$ & $\begin{array}{c}\text { SHR + 200 } \mathbf{~ m g} \\
(\boldsymbol{n}=\mathbf{1 0})\end{array}$ \\
\hline \multirow{2}{*}{ LDL } & $\mathrm{TP}(\mathrm{mg} / \mathrm{mL})$ & $1.6 \pm 0.1$ & $1.3 \pm 0.1$ & $1.1 \pm 0.1$ & $1.0 \pm 0.1$ & $0.8 \pm 0.1^{*}$ \\
& $\mathrm{TC}(\mathrm{mg} / \mathrm{mg})$ & $11.4 \pm 2.1$ & $9.3 \pm 0.8$ & $8.4 \pm 0.3$ & $7.5 \pm 0.4^{*}$ & $7.0 \pm 0.2^{*}$ \\
& $\mathrm{TG}(\mathrm{mg} / \mathrm{mg})$ & $3.1 \pm 0.1$ & $4.8 \pm 0.1$ & $4.4 \pm 0.1^{*}$ & $3.2 \pm 0.0^{* *}$ & $3.0 \pm 0.0^{* *}$ \\
\hline \multirow{2}{*}{$\mathrm{HDL}_{2}$} & $\mathrm{TP}(\mathrm{mg} / \mathrm{mL})$ & $2.8 \pm 0.2$ & $2.3 \pm 0.2$ & $2.2 \pm 0.2$ & $2.3 \pm 0.2$ & $3.2 \pm 0.2^{*}$ \\
& $\mathrm{TC}(\mathrm{mg} / \mathrm{mg})$ & $12.0 \pm 0.5$ & $6.6 \pm 0.2$ & $10.2 \pm 0.2^{* *}$ & $10.6 \pm 0.5^{* *}$ & $11.0 \pm 0.2^{* *}$ \\
& $\mathrm{TG}(\mathrm{mg} / \mathrm{mg})$ & $1.4 \pm 0.1$ & $1.7 \pm 0.1$ & $1.7 \pm 0.2$ & $1.5 \pm 0.1$ & $1.4 \pm 0.1^{*}$ \\
\hline \multirow{2}{*}{$\mathrm{HDL}_{3}$} & $\mathrm{TP}(\mathrm{mg} / \mathrm{mL})$ & $2.9 \pm 0.2$ & $2.7 \pm 0.2$ & $2.4 \pm 0.1$ & $2.6 \pm 0.1$ & $3.3 \pm 0.2^{*}$ \\
& $\mathrm{TC}(\mathrm{mg} / \mathrm{mg})$ & $4.2 \pm 0.1$ & $3.2 \pm 0.1$ & $4.1 \pm 0.1^{* *}$ & $4.3 \pm 0.2^{* *}$ & $4.5 \pm 0.2^{* *}$ \\
& $\mathrm{TG}(\mathrm{mg} / \mathrm{mg})$ & $0.9 \pm 0.0$ & $1.2 \pm 0.1$ & $1.1 \pm 0.0$ & $0.9 \pm 0.0^{*}$ & $0.8 \pm 0.0^{* *}$ \\
\hline
\end{tabular}

Data are expressed as mean \pm SD. WKY, normotensive Wistar Kyoto; SHR, Spontaneously hypertensive rats. HDL, high-density lipoproteins; LDL-C, low-density lipoprotein cholesterol; TC, total cholesterol; TG, triglyceride; $\mathrm{TP}$, total protein. ${ }^{* * *} p<0.001 \mathrm{vs}$. SHR + ND; ${ }^{* *} p<0.01 \mathrm{vs.} \mathrm{SHR} \mathrm{+} \mathrm{ND;} p<0.05 \mathrm{vs}$. SHR + ND in each group.

\subsection{Electrophoretic Profiles of $L D L$ and $H D L$}

In the immunodetection experiment, apo-B levels in LDL were not significantly different between the groups, as shown in Figure 6A, regardless of policosanol consumption. However, apoA-I band intensity in $\mathrm{HDL}_{3}$ was elevated (up to $83 \%$ ) in the $200 \mathrm{mg}$ of policosanol group, whereas other policosanol groups showed similar levels as the control.

\subsection{Electromobility of $L D L$}

As shown in Figure 6B, LDL from WKY rats showed more aggregated band in the loading position, whereas human LDL showed a clear and thick band. However, LDL from SHR showed faster electromobility than human LDL with greater smear intensity. The electromobility of rat LDL was slower in policosanol consumption group in a dose-dependent manner.
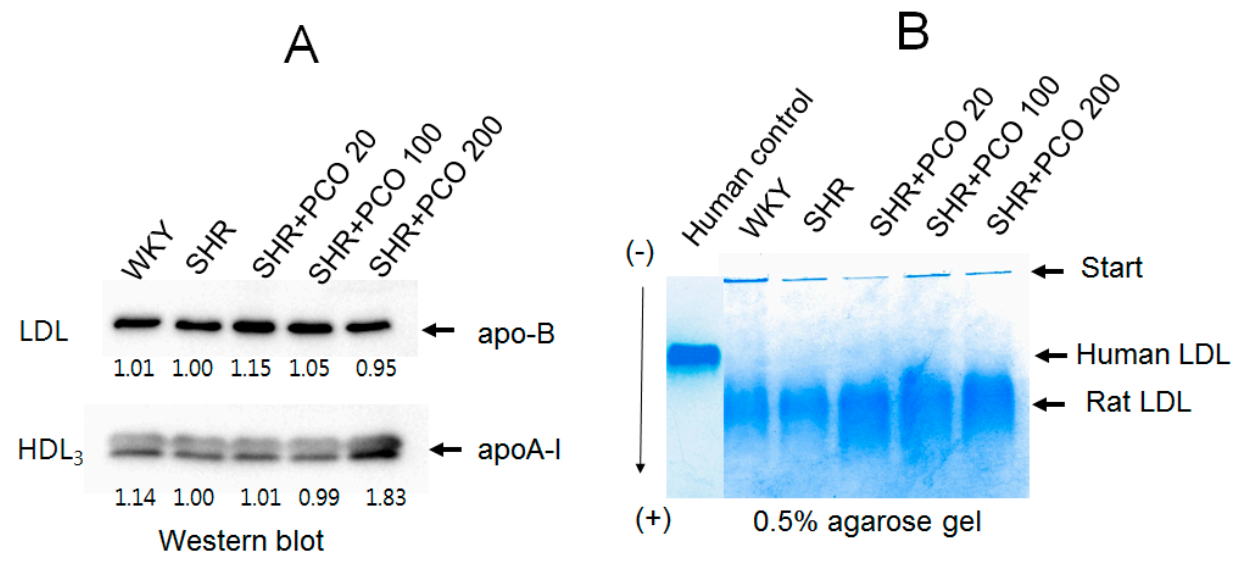

Figure 6. Electrophoretic profiles of LDL and HDL. (A) Immunodetection of LDL and $\mathrm{HDL}_{3}$ using anti-apoA-I and anti-apo-B antibodies. (B) Electromobility of LDL in agarose gel electrophoresis. 


\subsection{Aldosterone Levels in the Different Study Groups}

At week 2, the SHR control group showed a two-fold higher aldosterone level than the WKY group, as shown in Figure 7. At eight weeks, the SHR + ND (control) group showed a slight increment in the levels of aldosterone compared to week 0 . However, aldosterone level decreased in the policosanol groups in a dose-dependent manner. At week 8, the $200 \mathrm{mg}$ of policosanol group showed a serum aldosterone level of $66 \pm 10 \mathrm{pg} / \mathrm{mL}$ whereas the SHR control group showed a level of $193 \pm 25 \mathrm{pg} / \mathrm{mL}$.

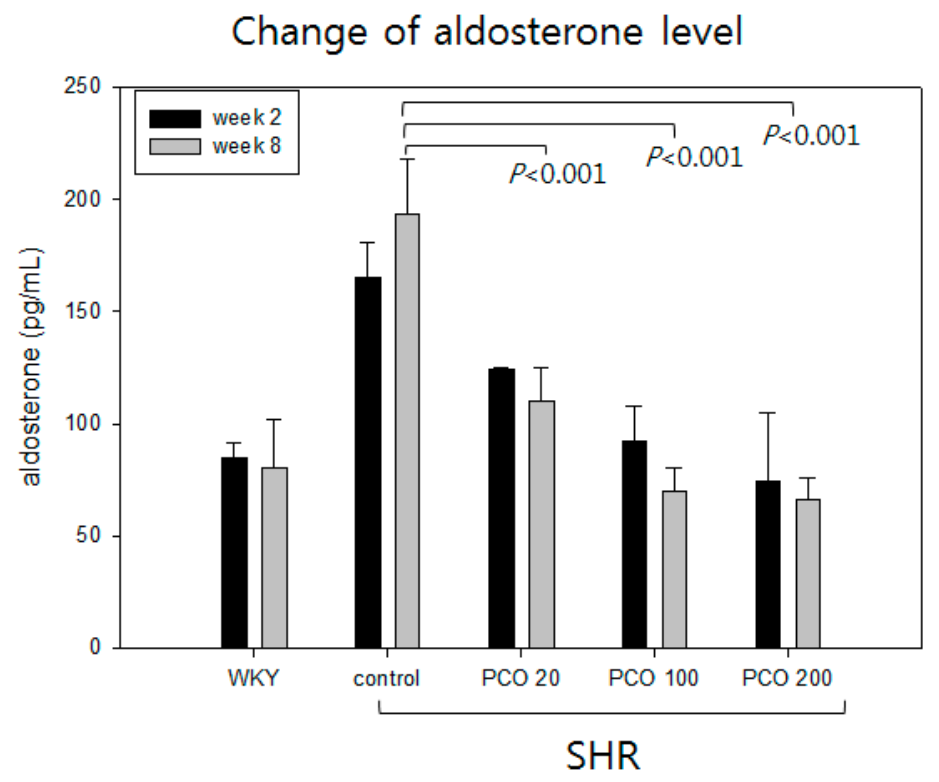

Figure 7. Changes in aldosterone level during eight weeks of policosanol consumption.

\subsection{Histologic Analysis of Hepatic Tissue}

The WKY control group showed normal hepatic lobulation and hepatocytes, as shown in Figure 8A. The SHR control showed loss of normal architecture as well as the presence of macroand microvesicular steatosis accompanied by inflammatory infiltrate and degenerative changes in hepatocytes. Lower doses of policosanol $(20 \mathrm{mg}$ and $100 \mathrm{mg})$ showed potential improvement along with moderate reinstatement of hepatic lobule architecture, moderate hepatocytes degeneration, and less infiltration of inflammatory cells, as indicated by the arrow in the figure. A higher dose of policosanol $200 \mathrm{mg}$ showed marked improvement accompanied by minimal fibrotic changes and less infiltration of inflammatory cells. Most hepatocytes looked normal and showed minimal residual degenerative changes, as shown in Figure 8A.

Determination of oxidized species in the homogenate of hepatic tissue revealed that the SHR + ND group had the highest content of MDA, which was four-fold higher than that of WKY control group (Figure 8B). However, the policosanol groups showed a remarkable reduction of MDA content in a dose-dependent manner. The SHR $+200 \mathrm{mg}$ of policosanol group contained $0.7 \mathrm{nmol}$ of MDA, which was an $85 \%$ reduction compared with that of the SHR + ND group (4.1 nmol of MDA). The SHR $+100 \mathrm{mg}$ of policosanol group showed a 50\% reduction in MDA content $(2.0 \mathrm{nmol})$ in liver extract, whereas the SHR $+20 \mathrm{mg}$ of policosanol group did not show a significant reduction. DHE staining showed that ROS production was 2.4-fold higher in the SHR + ND group than the WKY group (Figure 8C). However, the policosanol groups showed $18 \%, 39 \%$, and $53 \%$ reductions in DHE staining (Figure 8D). The $20 \mathrm{mg}, 100 \mathrm{mg}$, and $200 \mathrm{mg}$ of policosanol groups showed amelioration of hepatic inflammation and ROS production, as shown in Figure 8. 
A

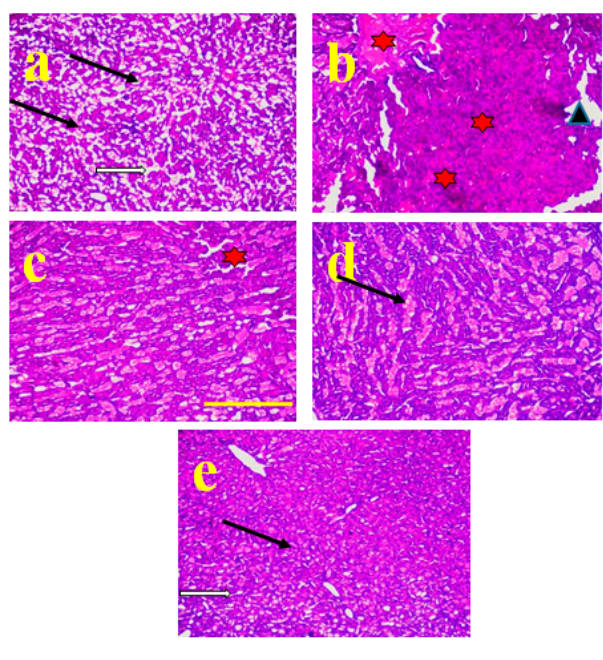

C

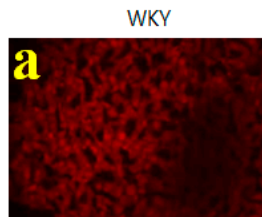

$\mathrm{SHR}+20 \mathrm{mg} \mathrm{PCO}$
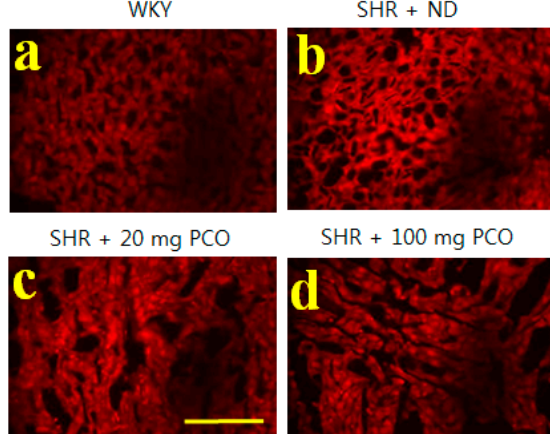

$\mathrm{SHR}+100 \mathrm{mg} \mathrm{PCO}$

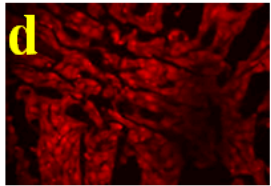

$\mathrm{SHR}+200 \mathrm{mg} \mathrm{PCO}$

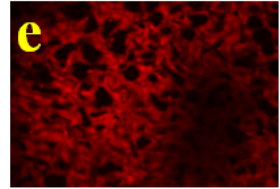

B

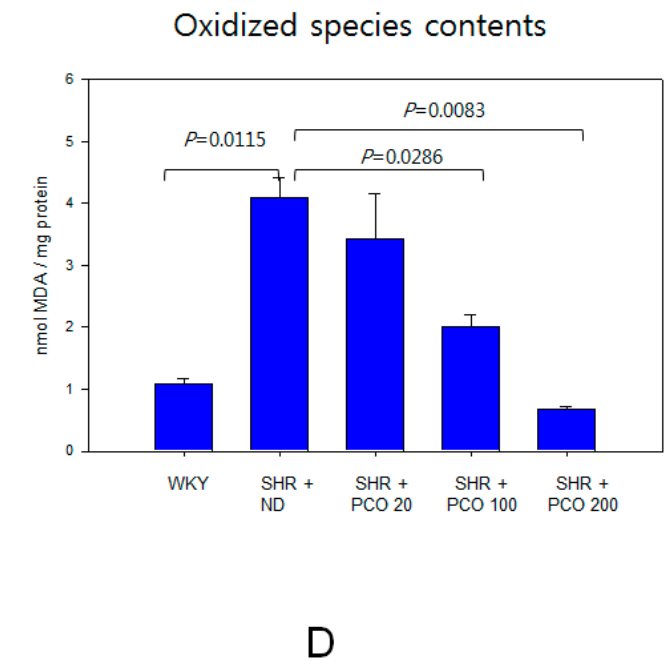

DHE stained area

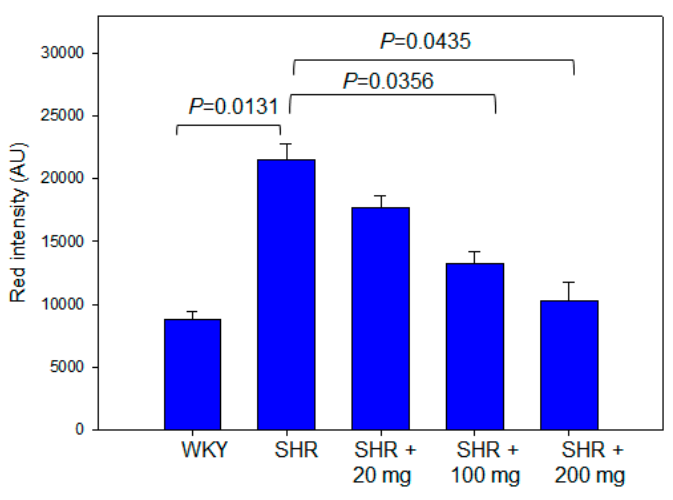

Figure 8. Liver histology by hematoxylin and eosin (H\&E) and DHE staining. The bar in the photo indicates $100 \mu \mathrm{m}$ (A) Representative image of histological changes in liver tissue observed by H\&E staining in normotensive (WKY) rats and spontaneously hypertensive rats (SHR). Photo a, Normal WKY group showing normal hepatic lobulation and hepatocytes. Photo b, SHR showing loss of normal architecture of hepatocytes (indicated by a triangle) and presence of leukocytes infiltrations (indicated by star shape) and degenerative changes in hepatocytes. Photo c, SHR $+20 \mathrm{mg}$ of policosanol (20 mg/ kg of body weight). Photo $\mathrm{d}, \mathrm{SHR}+100 \mathrm{mg}$ of policosanol (100 mg/ $\mathrm{kg}$ of body weight). Photo $\mathrm{c}$ and $\mathrm{d}$ show potential improvement along with moderate reinstatement of hepatic lobule architecture and less infiltration of leukocytes. Photo e, SHR $+200 \mathrm{mg}$ of policosanol $(200 \mathrm{mg} / \mathrm{kg}$ of body weight) depicted a normal tissue appearance, marked improvement of minimal inflammatory infiltrate, preservation of classical lobular pattern, and normal shape of sinusoids (white arrow). Scale bar indicates $100 \mu \mathrm{m}$ (Representative micrographs: magnification, $\times 100)$. (B) Quantification of oxidized species in hepatic tissue homogenate. (C) Visualization of ROS by DHE staining (Ex = $588 \mathrm{~nm}$, $\mathrm{Em}=615 \mathrm{~nm}$ ). (D) Quantification of DHE-stained area. Quantification of fluorescence in embryos using computer-assisted morphometry within the same area $\left(7.4 \mathrm{~mm}^{2}\right)$. Data are shown as the mean $\pm \mathrm{SD}$ of three independent experiments performed in duplicate. ${ }^{*} p<0.05 ;{ }^{* *} p<0.01$. The scale bar is $100 \mu \mathrm{m}$. 


\subsection{Correlation Analysis}

The Pearson's correlation analysis was performed mainly for the SHR $+100 \mathrm{mg}$ and SHR $+200 \mathrm{mg}$ of policosanol groups as shown in Supplementary Tables S1 and S2. The correlation study evaluated the relationship between blood pressure, HR, blood flow, and blood volume before and after eight weeks of policosanol treatment. The most significant correlation among these parameters was observed in the SHR + $200 \mathrm{mg}$ of policosanol group. SBP and DBP were positively correlated with blood flow and blood volume after eight weeks of policosanol treatment. The HR was not found to be significant in either group (SHR $+100 \mathrm{mg}$ of policosanol and SHR $+200 \mathrm{mg}$ of policosanol groups).

\section{Discussion}

Hypertension is a major risk factor for the development of metabolic syndrome and CVD, and is associated with high oxidative stress and aortic stiffness. SHR are the most common animal model of human essential hypertension [13-15] accompanied by preceding elevation of arterial stiffness. Policosanol enhances the beneficial functions of HDL and maximizes its antioxidant, anti-glycation, and anti-atherosclerotic activities $[6,7,9]$. Although short-term consumption of policosanol has been shown to reduce blood pressure as well as increase HDL-C level and functionality in a human study, no study has yet examined essential hypertension using an SHR model with a focus on lipid/lipoprotein levels.

As shown in Table 1, SBP and DBP of all SHR groups were not significantly different at week 0 . However, policosanol supplementation potently reduced SBP and DBP in SHR at week 8 (Table 1). The SHR + ND group showed a 1.2-fold increase in SBP and DBP compared to week 0. At week 0, the SHR + ND group showed a 1.3-fold higher HR than WKY rats, as reported previously [16]. Elevation of HR was accompanied by an increase in blood pressure in SHR and HR was reduced by policosanol consumption, as shown in Figure 1. In support of our current results, Wu et al. reported that normal WKY rats had a HR of $381 \pm 28 \mathrm{bpm}$, and SHR had a higher HR of $407 \pm 26 \mathrm{bpm}$. SHR fed losartan, a classic selective AT1 receptor antagonist that inhibits myocardial fibrosis, showed reduction of HR as well as SBP and DBP [17].

The SHR groups showed lower blood TC and HDL-C levels than the WKY groups. Another report supports our current results, which shows that SHR had 15\% lower HDL-C and 7\% lower TC concentration [18]. Although SHR had a smaller body weight than WKY rats, SHR had a much higher serum TG level and TG/HDL-C ratio than WKY rats. These results might be associated with higher CETP activity in SHR groups. It is well known that higher CETP activity is correlated with higher serum TG levels [19] and myocardial infarction in patients [20]. Our recent report using cord serum from small neonates also found that small neonates had a two-fold higher TG content and 1.2-fold higher CETP activity [21]. To the best of our knowledge, this is the first report to measure CETP activity in SHR and WKY rats which is crucial to monitor atherogenic dyslipidemia, and atherosclerotic CVD. It has been known that mouse and rat are very resistant to develop atherosclerosis since they do not have CETP activity $[22,23]$. However, SHR show a significant time-dependent elevation of CETP activity compared to WKY rats, suggesting that higher CETP activity is associated with elevated blood pressure. In a previous human study, plasma CETP activity was shown to be inversely related to change in SBP, but not related to change in DBP [24]. Moreover, consumption of $600 \mathrm{mg}$ of evacetrapib had no significant effects on either SBP or DBP compared with placebo [25].

In our previous report, policosanol in rHDL showed potent CETP inhibitory activity similar to that of anacetrapib [6,7], although policosanol showed less CETP inhibitory activity in ethanol. In the DEFINE Phase 3 safety study, anacetrapib was found to lower LDL-C and elevate HDL-C levels, whereas no changes in blood pressure or electrolyte or aldosterone levels [26].

Our current study reported that SHR treated with policosanol group after eight weeks recorded an elevation of paraoxonase activity in HDL, suggesting an enhancement in antioxidant capacity and functions. Policosanol could inhibit glycation of lipoproteins based on our previous reports $[7,9,10]$, advanced glycation end product could make stiffness in the blood vessel which causes to raise 
blood pressure [27]. Raising HDL-C [28] and inhibition of CETP activity [29] was associated with improvement of serum lipid profile that resulted in lowering blood pressure.

Previous reports have suggested that elevated aldosterone levels could increase the risk of hypertension [30,31]. Moreover, basic and clinical studies have demonstrated that the role of reninangiotensin-aldosterone system (RAAS) in hypertension [32,33]. Therefore, we examined the level of aldosterone in different groups (WKY, SHR, and SHR treated policosanol group) of animals. Our study reported a lowering of aldosterone in policosanol treated SHR group in a dose-dependent manner. This study proposed a mechanism for the blood pressure lowering effect of policosanol which is depicted in Figure 9. The inhibition of CETP activity, oxidation of LDL and glycation of HDL improves the aortic stiffness and thus lowers the blood pressure in SHR treated with policosanol.

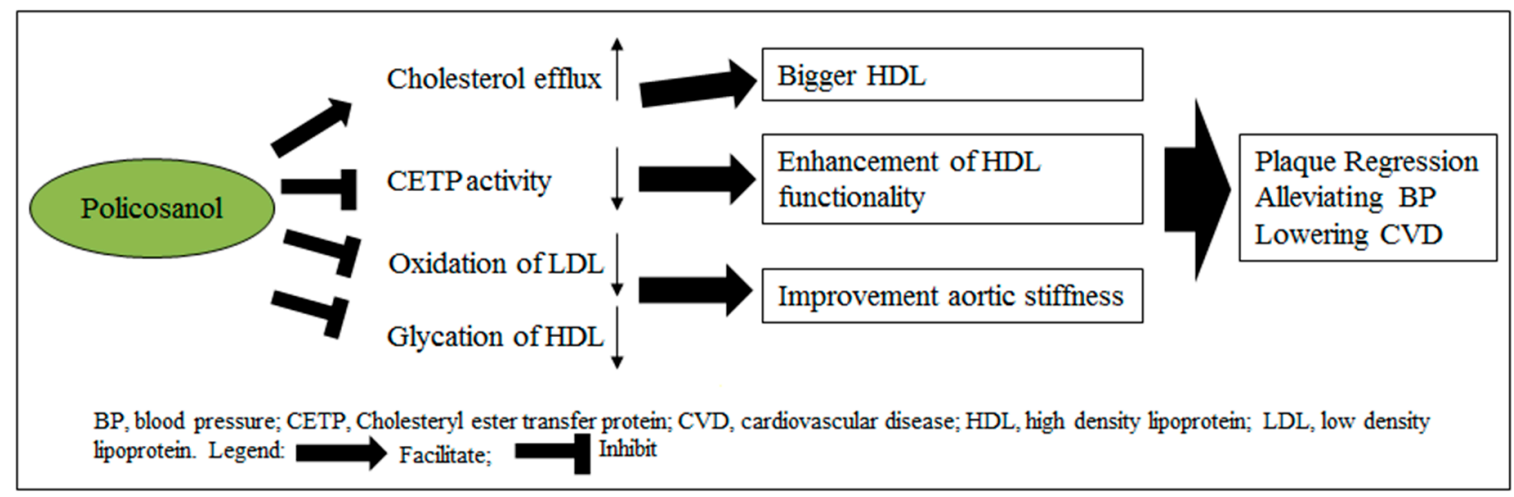

Figure 9. Proposed flow chart elucidating the mechanism of policosanol in lowering blood pressure.

From Pearson's correlation analysis, SBP and DBP at week 0 were shown to be inversely correlated with tail blood flow rate and tail blood volume. However, at week 8 , the relationship changed to be positive in a dose-dependent manner, especially in the SHR $+200 \mathrm{mg}$ of policosanol group. Previously these parameters were used to monitor blood pressure in various models $[34,35]$. The serum CRP level was 2.1-fold higher in SHR than in WKY rats, which is in good agreement with others reports $[36,37]$ and decreased upon policosanol consumption.

\section{Materials and methods}

\subsection{Animals and Diets}

Male spontaneously hypertensive rats (SHR/Izm; SHR, $n=50$ ), 10-weeks-old, and age-matched Wistar Kyoto normotensive (WKY/Izm) rats were purchased from Japan SLC, Inc (Hamamatsu, Japan). Experiments were performed in accordance with the Guiding Principles for the Care and Use of Laboratory Animals approved (2016-011) by the Committee of Animal Welfare of Yeungnam University (Gyeongsan, Korea). Rats were maintained on a 12-h light/dark cycle and allowed access to food and water ad libitum. After 2 weeks of acclimation, all rats were supplemented with each designated diet as shown in Table 1; normal diet (ND) alone, ND + $20 \mathrm{mg}, 100 \mathrm{mg}$, and $200 \mathrm{mg}$ of policosanol per $\mathrm{kg}$ of body weight for SHR and WKY rats consumed ND alone.

Policosanol (sugar cane wax alcohol, SCWA) was obtained from Rainbow \& Nature Pty, Ltd (Thornleigh, NSW, Australia). Policosanol consists of several alcohol chains of various lengths. Contents of the higher aliphatic alcohols were more than $90 \%$. The individual alcohols present in policosanol are 1-tetracosanol $\left(\mathrm{C}_{24} \mathrm{H}_{49} \mathrm{OH}\right.$; molecular weight $\left.(\mathrm{MW}): 354.7 \mathrm{m \mu}\right) \leq 2 \%$; 1-hexacosanol $\left(\mathrm{C}_{26} \mathrm{H}_{53} \mathrm{OH}\right.$; MW: $382.4 \mathrm{m \mu}) \leq 4.5-10 \%$; 1-heptacosanol $\left(\mathrm{C}_{27} \mathrm{H}_{55} \mathrm{OH} ; \mathrm{MW}: 396.4 \mathrm{m \mu}\right) \leq 5 \%$; 1-octacosanol $\left(\mathrm{C}_{28} \mathrm{H}_{57} \mathrm{OH}\right.$; MW: $410.5 \mathrm{m \mu}) \leq 60-70 \%$; 1-nonacosanol $\left(\mathrm{C}_{29} \mathrm{H}_{59} \mathrm{OH} ; \mathrm{MW}: 424.8 \mathrm{m \mu}\right) \leq 2 \%$; 1-triacontanol $\left(\mathrm{C}_{30} \mathrm{H}_{61} \mathrm{OH}\right.$; MW: $438.5 \mathrm{m \mu}) \leq 10-15 \%$; 1-dotriacontanol: $\left(\mathrm{C}_{32} \mathrm{H}_{65} \mathrm{OH}\right.$; MW: $\left.466.5 \mathrm{m \mu}\right) \leq 3-8 \%$; 1-tetratriacontanol $\left(\mathrm{C}_{34} \mathrm{H}_{69} \mathrm{OH} ; \mathrm{MW}: 494.5 \mathrm{~m} \mu\right) \leq 2 \%$. Policosanol was mixed with powder of purified rodent diet AIN-76A 
(Dyets, Inc, Bethlehem, PA, USA) to produce daily contents of 20, 100, and $200 \mathrm{mg}$ of policosanol $/ \mathrm{kg}$ of body weight. The mixtures were then re-pelleted and stored at $4{ }^{\circ} \mathrm{C}$ during the 8 -weeks feeding period.

\subsection{Measurement of Blood Pressure}

Systolic blood pressure (SBP) and diastolic blood pressure (DBP) were measured using a CODA ${ }^{\mathrm{TM}}$ monitor (Kent Scientific Co, Torrington, CT, USA), a computerized, non-invasive blood pressure monitor, according to the owner's manual using the tail-cuff manometry. Heart rate (HR, bpm), blood volume $(\mu \mathrm{L})$, and flow rate $(\mathrm{mL} / \mathrm{min})$ were also measured using the CODA ${ }^{\mathrm{TM}}$ monitor equipped with a volume pressure recording sensor. Baseline blood pressure and HR measurements were recorded for 7 days before the initiation of policosanol consumption. During consumption, blood pressure was recorded at 2-week intervals after training the animals. The procedure of measuring blood pressure are as follow, unanesthetized rats were controlled in a plastic tube, that was positioned on a heating pad for the maintenance of the body temperature and to establish ample blood flow to the tails. Each rat was allowed to adjust to the restrainer for 5-7 $\mathrm{min}$ and then measure blood pressure. The volume-pressure recording determines the tail blood volume using a volume pressure recording sensor and an occlusion tail-cuff. It measures the SBP, DBP, heart rate, tail blood volume, and tail blood flow. SBP and DBP were recorded three times blind to the randomization sequence at each interval and average values were calculated. The CODA ${ }^{\mathrm{TM}}$ monitor system includes a controller, laptop computer, software, cuffs, animal holders, infrared warming pads, and an infrared thermometer.

\subsection{Plasma Analysis}

After 8 weeks of policosanol intake, blood was obtained from rats by heart puncture following overnight fasting. During consumption, small blood samples were collected from each tail vein and stored in an Eppendorf tube containing EDTA at 2, 4 and 8 weeks. Plasma was separated by low-speed centrifugation $(3000 \mathrm{~g})$ and stored at $-80^{\circ} \mathrm{C}$. TC, TG, HDL-C, glucose, GOT, and GPT levels were analyzed by using the available kits (Cleantech TS-S; Wako Pure Chemical, Osaka, Japan). LDL-cholesterol (LDL-C) was calculated using the Friedewald formula: $\mathrm{LDL}-\mathrm{C}=\mathrm{TC}-(\mathrm{HDL}-\mathrm{C}+(\mathrm{TG} / 5))$.

\subsection{Purification and Analysis of Lipoproteins}

A sequential ultracentrifugation were used to separate very low-density lipoproteins (VLDL, $\mathrm{d}<1.019 \mathrm{~g} / \mathrm{mL}), \mathrm{LDL}(1.019<\mathrm{d}<1.063), \mathrm{HDL}_{2}(1.063<\mathrm{d}<1.125)$, and $\mathrm{HDL}_{3}(1.125<\mathrm{d}<1.225)$ from the serum of each group [38]. Moreover, the density was adjusted by supplementation of $\mathrm{NaCl}$ and $\mathrm{NaBr}$ based on the standard protocols. Blood was centrifuged for $24 \mathrm{~h}$ at $10^{\circ} \mathrm{C}$ at $100,000 \mathrm{~g}$ using a Himac CP100NX (Hitachi, Tokyo, Japan) using P50AT4-0124 rotor in our laboratory.

The concentration of Protein from the lipoproteins were calculated by Lowry protein assay, further modified by Markwell et al. [39]. To quantify the oxidation of each LDL, the amount of oxidized species in LDL was measured by the thiobarbituric acid reactive substances (TBARS) method [40].

\subsection{Oxidation of LDL by Cupric Ion}

To measure the susceptibility of cupric ion-mediated LDL oxidation, $300 \mu \mathrm{g}$ of LDL was nurtured with $10 \mu \mathrm{M} \mathrm{CuSO}_{4}$ for up to $3 \mathrm{~h}$. The quantity of conjugated dienes formation was observed by measuring absorbance at $234 \mathrm{~nm}\left(\mathrm{Abs}_{234}\right)$ at $37^{\circ} \mathrm{C}$ [41] using a Beckman DU 800 spectrophotometer. To corroborate the spectroscopic data, oxLDL samples were loaded on $0.5 \%$ agarose gel electrophoresis to differentiate relative electromobilities [42]. The electrophoretic mobility of each LDL was examined by $0.5 \%$ agarose gel electrophoresis. More oxidized LDL travel faster towards the bottom of the gel than less oxidized or native LDL, and electrical properties of oxLDL were shifted with a reduced size because of apo-B fragmentation. 


\subsection{Assay for Cholesteryl Ester Transfer Protein}

A rHDL-containing apoA-I and cholesteryl oleate were synthesized based on the method reported by Cho [43]. Briefly, lipids (POPC, cold cholesteryl oleate, and $\left[{ }^{3} \mathrm{H}\right]$-cholesteryl oleate) were mixed in a glass vial and gently vortexed, followed by drying under a $\mathrm{N}_{2}$ gas stream at $37^{\circ} \mathrm{C}$. After drying, the lipids were dispersed by addition of TBS with slight agitation. Phospholipid bilayer formation was facilitated by the addition of sodium cholate and apoA-I. After extensive dialysis for $24 \mathrm{~h}$ to remove cholate, $\left[{ }^{3} \mathrm{H}\right]-\mathrm{CE}-\mathrm{rHDL}$ was recovered and characterized by scintillation counting and protein determination.

The $\left[{ }^{3} \mathrm{H}\right]-\mathrm{CE}-\mathrm{rHDL}$ was incapacitated using $\mathrm{CNBr}$-activated Sepharose 4B resin from Amersham Biosciences for trouble-free separation after the reaction, according to the manufacturer's protocol. CE transfer reaction was done in $300-\mu \mathrm{L}$ reaction mixtures consisting of human serum $(20 \mu \mathrm{L})$ or $\mathrm{HDL}_{3}(20 \mu \mathrm{L}, 2 \mathrm{mg} / \mathrm{mL})$ as a potential source of CETP. Human LDL $(20 \mu \mathrm{L}, 0.25 \mathrm{mg} / \mathrm{mL})$ acts as a CE-acceptor while $\left[{ }^{3} \mathrm{H}\right]-$ rHDL-agarose $(20 \mu \mathrm{L}, 0.25 \mathrm{mg} / \mathrm{mL})$ as a CE-donor. After incubation of $4 \mathrm{~h}$ at $37^{\circ} \mathrm{C}$, the reaction was halted by a brief centrifugation $(10,000 \mathrm{~g})$ for $3 \mathrm{~min}$ at $4{ }^{\circ} \mathrm{C}$. The supernatant containing $\mathrm{CE}$-acceptor $(150 \mu \mathrm{L})$ was used in scintillation counting for measuring the ionizing radiation and $\%$ transfer of $\left[{ }^{3} \mathrm{H}\right]-\mathrm{CE}$ from $\left[{ }^{3} \mathrm{H}\right]-$-rHDL to LDL was quantified.

\subsection{Paraoxonase Assay}

Paraoxonase-1 (PON-1) activity was determined by measuring the initial velocity of $p$-nitrophenol production at $37^{\circ} \mathrm{C}$ based on its absorbance at $405 \mathrm{~nm}$ (microplate reader, Bio-Rad model 680; Bio-Rad, Hercules, CA, USA), as described previously [44] with slight modification [45]. Prior to the measurement, HDL was thoroughly dialyzed against PBS to eliminate EDTA.

\subsection{ELISA and Western Blotting}

To quantify aldosterone and C-reactive protein (CRP) in plasma, an aldosterone ELISA kit (ab136933) and rat CRP ELISA kit (PTX1, ab108827), respectively, were obtained from Abcam (Cambridge, UK). Appropriately diluted plasma samples were reacted using the kit in according to the manufacturer's suggestion.

The composition of apolipoprotein/lipoprotein were analyzed by sodium dodecyl sulfate-polyacrylamide gel electrophoresis (SDS-PAGE) with an exact amount of protein loaded in the gel (5 $\mathrm{\mu g}$ of total protein per lane) from individual $\mathrm{HDL}_{3}$, and the levels of apolipoprotein expression were measured by immunodetection. Anti-human apoA-I antibody (ab7613) and anti-apo-B antibody (ab20737) were ordered from Abcam (Cambridge, UK). Relative band intensity (BI) was compared through band scanning with Chemi-Doc ${ }^{\circledR}$ XRS+ (Bio-Rad, Hercules, CA, USA) using Image Lab software (Version 5.2, Bio-Rad, Hercules, CA, USA). Blot images are imported into the Quantity One software and then contrast was adjusted in a way so that the bands were fully noticeable on the blot image. The area around the band was chosen; additionally, the background intensity was deducted from the blot image. The appropriate bands were used to calculate band intensities and exported to excel for analysis.

\subsection{Histologic Analysis}

The livers of the sacrificed rats were fixed in $4 \%$ paraformaldehyde for $24 \mathrm{~h}$. Fixed tissues were then inserted in Tissue-Tek OCT compound (Thermo, Walldorf, Germany) and frozen. After frozen the tissue blocks were fixed in a model Leica CM1510S cryotome (Nussloch, Germany), and 7- $\mu \mathrm{m}$ sections of individual tissue were placed on 3-aminopropyltriethoxysilane-coated slides. Six to seven successive sectioned slides from each rat were stained with hematoxylin and eosin according to the standard protocols.

To compare the oxidative stress in tissues, ROS levels were imaged using dihydroethidium (DHE, cat \# 37291; Sigma, St. Louis, MO, USA) as described previously [46]. The image was seen by 
fluorescence $(E x=588 \mathrm{~nm}$ and $E \mathrm{~m}=615 \mathrm{~nm})$ using a Nikon Eclipse TE2000 microscope (Tokyo, Japan). Image-Pro plus software (version 4.5.1.22; Media Cybernetics, Bethesda, MD, USA) were used for the quantification of section fluorescence.

Aliquots of liver tissue (50 mg of liver in $0.5 \mathrm{~mL}$ of PBS) from all groups were homogenized for $3 \mathrm{~min}(150 \mathrm{rpm})$ using a tissue homogenizer with a standard protocol (Euro-ST; Eurostar, IKA-WERKE, Staufen, Germany). After centrifugation $(10,000 \mathrm{~g})$ Bradford reagent was used for the protein determination; equally diluted supernatants $(100 \mu \mathrm{g}$ of protein in $0.05 \mathrm{~mL})$ were used for quantification of oxidative species by the thiobarbituric acid reactive species (TBARS) method [40].

\subsection{Data Analysis}

The data of this study are expressed as the mean \pm SD from at least three independent experiments with duplicate samples. For the rat study, multiple groups were compared using one-way analysis of variance (ANOVA) between the five groups using Scheffe test. Correlation analysis was carried out using Pearson's test. Statistical analysis was performed by SPSS software program (version 23.0; SPSS, Inc., Chicago, IL, USA). A $p$ value $<0.05$ was considered statistically significant.

\section{Conclusions}

In conclusion, eight weeks of policosanol consumption by SHR resulted in remarkable reduction of blood pressure, serum aldosterone, and serum TG levels, elevation of HDL-C level and lipoprotein functionality, and improvement of hepatic inflammation.

Supplementary Materials: The following are available online.

Author Contributions: K.-H.C., D.Y. and S.-J.K. conceived and designed the experiments; K.-H.C., D.Y., S.-J.K. and J.-R.K. performed experiments; J.-R.K. analyzed data and D.Y. and S.-J.K helps in the preparation of the initial draft; K.-H.C. wrote the manuscript and supervised the whole project.

Acknowledgments: This work was supported by a grant from the Medical Research Center Program (2015R1A5A2009124) through the National Research Foundation (NRF) funded by the Ministry of Science, ICT, and Future Planning of Korea.

Conflicts of Interest: The authors declare no conflicts of interest.

\section{References}

1. Laaksonen, D.E.; Niskanen, L.; Nyyssönen, K.; Lakka, T.A.; Laukkanen, J.A.; Salonen, J.T. Dyslipidaemia as a predictor of hypertension in middle-aged men. Eur. Heart J. 2008, 29, 2561-2568. [CrossRef] [PubMed]

2. Sánchez-Íñigo, L.; Navarro-González, D.; Pastrana-Delgado, J.; Fernández-Montero, A.; Martínez, J.A. Association of triglycerides and new lipid markers with the incidence of hypertension in a spanish cohort. J. Hypertens. 2016, 34, 1257-1265. [CrossRef] [PubMed]

3. González, J.; Valls, N.; Brito, R.; Rodrigo, R. Essential hypertension and oxidative stress: New insights. World J. Cardiol. 2014, 6, 353-366. [CrossRef] [PubMed]

4. Boyce, G.; Button, E.; Soo, S.; Wellington, C. The pleiotropic vasoprotective functions of high density lipoproteins (HDL). J. Biomed. Res. 2017. [CrossRef]

5. Gong, J.; Qin, X.; Yuan, F.; Hu, M.; Chen, G.; Fang, K.; Wang, D.; Jiang, S.; Li, J.; Zhao, Y. Efficacy and safety of sugarcane policosanol on dyslipidemia: A meta-analysis of randomized controlled trials. Mol. Nutr. Food Res. 2018, 62. [CrossRef] [PubMed]

6. Lim, S.-M.; Yoo, J.-A.; Lee, E.-Y.; Cho, K.-H. Enhancement of high-density lipoprotein cholesterol functions by encapsulation of policosanol exerts anti-senescence and tissue regeneration effects via improvement of anti-glycation, anti-apoptosis, and cholesteryl ester transfer inhibition. Rejuvenation Res. 2016, 19, 59-70. [CrossRef] [PubMed]

7. Lee, E.-Y.; Yoo, J.-A.; Lim, S.-M.; Cho, K.-H. Anti-aging and tissue regeneration ability of policosanol along with lipid-lowering effect in hyperlipidemic zebrafish via enhancement of high-density lipoprotein functionality. Rejuvenation Res. 2016, 19, 149-158. [CrossRef] [PubMed] 
8. Singh, D.K.; Li, L.; Porter, T.D. Policosanol inhibits cholesterol synthesis in hepatoma cells by activation of amp-kinase. J. Pharmacol. Exp. Ther. 2006, 318, 1020-1026. [CrossRef] [PubMed]

9. Kim, J.-Y.; Kim, S.-M.; Kim, S.-J.; Lee, E.-Y.; Kim, J.-R.; Cho, K.-H. Consumption of policosanol enhances HDL functionality via CETP inhibition and reduces blood pressure and visceral fat in young and middle-aged subjects. Int. J. Mol. Med. 2017, 39, 889-899. [CrossRef] [PubMed]

10. Kim, S.-J.; Yadav, D.; Park, H.-J.; Kim, J.-R.; Cho, K.-H. Long-term consumption of cuban policosanol lowers central and brachial blood pressure and improves lipid profile with enhancement of lipoprotein properties in healthy korean participants. Front. Physiol. 2018, 9, 412. [CrossRef]

11. Castano, G.; Mas, R.; Fernandez, J.C.; Fernandez, L.; Illnait, J.; Lopez, E. Effects of policosanol on older patients with hypertension and type ii hypercholesterolaemia. Drugs $R$ D 2002, 3, 159-172. [CrossRef] [PubMed]

12. Trippodo, N.C.; Frohlich, E.D. Similarities of genetic (spontaneous) hypertension. Man and rat. Circ. Res. 1981, 48, 309-319. [CrossRef] [PubMed]

13. Lemmer, B.; Mattes, A.; Böhm, M.; Ganten, D. Circadian blood pressure variation in transgenic hypertensive rats. Hypertension 1993, 22, 97-101. [CrossRef] [PubMed]

14. Leong, X.-F.; Ng, C.-Y.; Jaarin, K. Animal Models in Cardiovascular Research: Hypertension and Atherosclerosis. Biomed. Res. Int. 2015, 2015, 528757. [CrossRef] [PubMed]

15. Badyal, D.; Dadhich, A.; Lata, H. Animal models of hypertension and effect of drugs. Indian J. Pharmacol. 2003, 35, 349-362.

16. Andrzejczak, D.; Górska, D. The effects of celiprolol on serum concentrations of proinflammatory cytokines in hypertensive (SHR) and normotensive (WKY) rats. Pharmacol. Rep. 2014, 66, 68-73. [CrossRef] [PubMed]

17. Wu, M.; Peng, Z.; Zu, C.; Ma, J.; Lu, S.; Zhong, J.; Zhang, S. Losartan attenuates myocardial endothelial-to-mesenchymal transition in spontaneous hypertensive rats via inhibiting TGF- $\beta$ /Smad Signaling. PLoS ONE 2016, 11, e0155730. [CrossRef] [PubMed]

18. Simic, B.; Hermann, M.; Shaw, S.G.; Bigler, L.; Stalder, U.; Dorries, C.; Besler, C.; Luscher, T.F.; Ruschitzka, F. Torcetrapib impairs endothelial function in hypertension. Eur. Heart J. 2012, 33, 1615-1624. [CrossRef] [PubMed]

19. Yang, S.; Chen, X.Y.; Xu, X.P. The Relationship Between Lipoprotein-Associated Phospholipase A(2), Cholesteryl Ester Transfer Protein and Lipid Profile and Risk of Atherosclerosis in Women with Iron Deficiency Anaemia. Clin. Lab. 2015, 61, 1463-1469. [CrossRef] [PubMed]

20. Cho, K.H.; Shin, D.G.; Baek, S.H.; Kim, J.R. Myocardial infarction patients show altered lipoprotein properties and functions when compared with stable angina pectoris patients. Exp. Mol. Med. 2009, 41, 67-76. [CrossRef] [PubMed]

21. Kim, S.M.; Lee, S.M.; Kim, S.J.; Kim, B.J.; Shin, S.; Kim, J.R.; Cho, K.H. Cord and maternal sera from small neonates share dysfunctional lipoproteins with proatherogenic properties: Evidence for Barker's hypothesis. J. Clin. Lipidol. 2017, 11, 1318-1328. [CrossRef] [PubMed]

22. Ha, Y.C.; Barter, P.J. Differences in plasma cholesteryl ester transfer activity in sixteen vertebrate species. Comp. Biochem. Physiol. Part B Comp. Biochem. 1982, 71, 265-269. [CrossRef]

23. Davidson, M.H. Update on CETP inhibition. J. Clin. Lipidol. 2010, 4, 394-398. [CrossRef] [PubMed]

24. Zachariah, J.P.; Pencina, M.J.; Lyass, A.; Kaur, G.; D’agostino, R.B.; Ordovas, J.M.; Vasan, R.S. Circulating plasma cholesteryl ester transfer protein activity and blood pressure tracking in the community. J. Hypertens. 2011, 29, 863-868. [CrossRef] [PubMed]

25. Suico, J.G.; Wang, M.D.; Friedrich, S.; Cannady, E.A.; Konkoy, C.S.; Ruotolo, G.; Krueger, K.A. Effects of the cholesteryl ester transfer protein inhibitor evacetrapib on lipoproteins, apolipoproteins and 24-h ambulatory blood pressure in healthy adults. J. Pharm. Pharmacol. 2014, 66, 1576-1585. [CrossRef] [PubMed]

26. Cannon, C.P.; Shah, S.; Dansky, H.M.; Davidson, M.; Brinton, E.A.; Gotto, A.M., Jr.; Stepanavage, M.; Liu, S.X.; Gibbons, P.; Ashraf, T.B. Safety of anacetrapib in patients with or at high risk for coronary heart disease. N. Engl. J. Med. 2010, 363, 2406-2415. [CrossRef] [PubMed]

27. Mayer, O.; Seidlerova, J.; Filipovsky, J.; Vagovicova, P.; Wohlfahrt, P.; Cifkova, R.; Windrichova, J.; Topolcan, O. Soluble receptor for advanced glycation end products and increased aortic stiffness in the general population. Hypertens. Res. 2016, 39, 266-271. [CrossRef] [PubMed] 
28. Mandai, N.; Akazawa, K.; Hara, N.; Ide, Y.; Ide, K.; Dazai, U.; Chishaki, A.; Chishaki, H. Body weight reduction results in favorable changes in blood pressure, serum lipids, and blood sugar in middle-aged japanese persons: A 5-year interval observational study of 26,824 cases. Glob. J. Health Sci. 2015, 7, 159-170. [CrossRef] [PubMed]

29. Barter, P.J.; Rye, K.-A. Cholesteryl ester transfer protein inhibition as a strategy to reduce cardiovascular risk. J. Lipid Res. 2012, 53, 1755-1766. [CrossRef] [PubMed]

30. Tomaschitz, A.; Maerz, W.; Pilz, S.; Ritz, E.; Scharnagl, H.; Renner, W.; Boehm, B.O.; Fahrleitner-Pammer, A.; Weihrauch, G.; Dobnig, H. Aldosterone/renin ratio determines peripheral and central blood pressure values over a broad range. J. Am. Coll. Cardiol. 2010, 55, 2171-2180. [CrossRef] [PubMed]

31. Vasan, R.S.; Evans, J.C.; Larson, M.G.; Wilson, P.W.; Meigs, J.B.; Rifai, N.; Benjamin, E.J.; Levy, D. Serum aldosterone and the incidence of hypertension in nonhypertensive persons. N. Engl. J. Med. 2004, 351, 33-41. [CrossRef] [PubMed]

32. Manrique, C.; Lastra, G.; Gardner, M.; Sowers, J.R. The Renin Angiotensin Aldosterone System in Hypertension: Roles of Insulin Resistance and Oxidative Stress. Med. Clin. N. Am. 2009, 93, 569-582. [CrossRef] [PubMed]

33. Streeten, D.P.; Clift, G.V.; Schletter, F.E.; Dalakos, T.S. The renin-angiotensin-aldosterone system in hypertension. Ann. Intern. Med. 1968, 68, 1164. [CrossRef]

34. Malkoff, J. Non-invasive blood pressure for mice and rats. Anim. Lab News Kent Sci. Corp. 2005, 1-12.

35. Fouad-Tarazi, F.; Calcatti, J.; Christian, R.; Armstrong, R.; Depaul, M. Blood volume measurement as a tool in diagnosing syncope. Am. J. Med. Sci. 2007, 334, 53-56. [CrossRef] [PubMed]

36. Yamaguchi, Y.; Yoshikawa, N.; Kagota, S.; Nakamura, K.; Haginaka, J.; Kunitomo, M. Elevated circulating levels of markers of oxidative-nitrative stress and inflammation in a genetic rat model of metabolic syndrome. Nitric Oxide 2006, 15, 380-386. [CrossRef] [PubMed]

37. Pravenec, M.; Kajiya, T.; Zídek, V.; Landa, V.; Mlejnek, P.; Šimáková, M.; Šilhavý, J.; Malínská, H.; Oliyarnyk, O.; et al. Effects of Human C-Reactive Protein on Pathogenesis of Features of the Metabolic Syndrome. Hypertension 2011, 57. [CrossRef] [PubMed]

38. Havel, R.J.; Eder, H.A.; Bragdon, J.H. The distribution and chemical composition of ultracentrifugally separated lipoproteins in human serum. J. Clin. Investig. 1955, 34, 1345-1353. [CrossRef] [PubMed]

39. Markwell, M.A.; Haas, S.M.; Bieber, L.L.; Tolbert, N.E. A modification of the Lowry procedure to simplify protein determination in membrane and lipoprotein samples. Anal. Biochem. 1978, 87, 206-210. [CrossRef]

40. Blois, M.S. Antioxidant determinations by the use of a stable free radical. Nature 1958, 181, 1199-1200. [CrossRef]

41. Esterbauer, H.; Striegl, G.; Puhl, H.; Rotheneder, M. Continuous monitoring of in vitro oxidation of human low density lipoprotein. Free Radic. Res. Commun. 1989, 6, 67-75. [CrossRef] [PubMed]

42. Noble, R.P. Electrophoretic separation of plasma lipoproteins in agarose gel. J. Lipid Res. 1968, 9, $693-700$. [PubMed]

43. Cho, K.-H. Synthesis of reconstituted high density lipoprotein (rHDL) containing apoA-I and apoC-III: The functional role of apoC-III in rHDL. Mol. Cells 2009, 27, 291-297. [CrossRef] [PubMed]

44. Eckerson, H.W.; Wyte, C.M.; la Du, B. The human serum paraoxonase/arylesterase polymorphism. Am. J. Hum. Genet. 1983, 35, 1126-1138. [PubMed]

45. Park, K.-H.; Shin, D.-G.; Kim, J.-R.; Hong, J.-H.; Cho, K.-H. The functional and compositional properties of lipoproteins are altered in patients with metabolic syndrome with increased cholesteryl ester transfer protein activity. Int. J. Mol. Med. 2010, 25, 129-136. [PubMed]

46. Owusu-Ansah, E.; Yavari, A.; Mandal, S.; Banerjee, U. Distinct mitochondrial retrograde signals control the G1-S cell cycle checkpoint. Nat. Genet. 2008, 40, 356-361. [CrossRef] [PubMed]

Sample Availability: Samples of the compounds are available from the authors. 